\title{
Mutual impact of reservoir sands and acidic liquid radioactive waste
}

\author{
Irina Vlasova ${ }^{1, *}$, Anna Romanchuk ${ }^{1}$, Ilya Gusev ${ }^{1}$, Anna Volkova ${ }^{2}$, Elena Zakharova ${ }^{2}$, \\ Alexandra Rzhevskaia ${ }^{1}$, and Stepan Kalmykov ${ }^{1}$ \\ ${ }^{1}$ Lomonosov Moscow State University, Department of Chemistry, 119991 Leninskie Gory, 1 bld.3, \\ Russia \\ ${ }^{2}$ Frumkin Institute of Physical Chemistry and Electrochemistry, RAS, Leninskii pr., 31, korp.4, \\ Moscow, Russia
}

\begin{abstract}
The work is devoted to the study of the behavior of long-lived alpha-emitting radionuclides $(\mathrm{Pu}, \mathrm{Am}, \mathrm{U}, \mathrm{Np})$ under the conditions of injection of acidic liquid radioactive waste into a sandy rock reservoir bed. Different mineral phases of initial reservoir sands, secondary minerals formed when interacting with waste solutions, as well as phases precipitating from the waste solution are considered in terms of their retention properties towards to actinides.
\end{abstract}

\section{Introduction}

The development of nuclear programs in the last century has led to the accumulation of large amounts of liquid radioactive waste (LRW) concentrated in local sites, and their presence on the surface of the earth posed a great danger. One of the solutions to this problem was the deep-well injection of LRW into aquifer reservoirs [1]. The Seversk site (JSC Siberian Chemical Combine, Russia) has the most extensive experience of LRW isolation into the water-permeable strata since 1963. Today the reservoir is a complex natural - man-made system formed as a result of long interaction of sand with LRW of different composition. The study of this system is of practical interest for the prediction of the spread of contamination in the environment, as well as fundamental interest in terms of expanding our knowledge about the migration behavior of radionuclides, especially redoxsensitive actinides, in various geochemical conditions.

The waste has a different composition including acidic technological waste with $\mathrm{pH} 2.5$, which consist of sodium nitrate, acetic acid, dissolved corrosion products ( $\mathrm{Fe}, \mathrm{Cr}, \mathrm{Mn}, \mathrm{Ni}$, Al) and radionuclides. This paper presents the results of studies of the reservoir sands interaction with acidic waste injected to the reservoir that pose the greatest danger due to the presence of long-lived alpha-emitting radionuclides $\left({ }^{239} \mathrm{Pu},{ }^{238},{ }^{235} \mathrm{U},{ }^{241},{ }^{243} \mathrm{Am},{ }^{237} \mathrm{~Np}\right)$. The identification of the main sorption phases along with the establishment of sorption mechanisms have become key objectives of this work.

\footnotetext{
* Corresponding author: irinaeng@gmail.com
} 


\section{Methodology}

The study of the reservoir bed requires a special methodological approach due to the difficulty of sampling from the LRW injection site on the one hand, and because of the need to forecast the migration of long-lived radionuclides tens of thousands of years ahead. The complex ternary system "sands of the reservoir bed - corrosion products precipitated from LRW solution - long-lived radionuclides" has been studied in parts in strictly controlled laboratory conditions. The actual coarse-medium-grained sandy rocks from the reservoir bed were used. They consist of quartz (60-75\%), feldspar (5-10\%), clay minerals $(5-15 \%)$, mica (1-5\%), argillite fragments and organic matter. The simulated LRW solution with the following composition $(\mathrm{g} / \mathrm{L}): \mathrm{NaNO}_{3}-142 ; \mathrm{Al}-0.1 ; \mathrm{Fe}-0.35 ; \mathrm{Cr}-0.37 ; \mathrm{Mn}-$ $0.61 ; \mathrm{Ni}-0.37 ; \mathrm{CH}_{3} \mathrm{COOH}-20$ was used. The spikes of ${ }^{239} \mathrm{Pu},{ }^{241} \mathrm{Am},{ }^{237} \mathrm{~Np}$ and ${ }^{232} \mathrm{U}$ were added separately to LRW solutions to achieve the individual specific activity of each nuclide of $5.0 \cdot 10^{4} \mathrm{~Bq} / \mathrm{L}$.

Several series of experiments have been carried out that simulated the conditions of the reservoir during the injection of acidic technological waste. To determine the phases formed during the interaction of sand with LRW, actual sands of the reservoir and simulated solutions of LRW with different concentrations of dissolved corrosion products and radionuclides have been used. With an increase in the distance from the injection zone, the acid solutions are neutralized with sands from the bed and are partially diluted with natural waters, which is accompanied by an increase in $\mathrm{pH}$ up to $\mathrm{pH} 8.0$ (migration zone).The $\mathrm{pH}$ values of the experimental solution have varied in accordance with the gradual dilution of acidic waste with natural waters of the reservoir (from 2.4; till 8.0). The temperature also has varied from $100-150^{\circ} \mathrm{C}$ to $50^{\circ} \mathrm{C}$, in accordance with the conditions of the reservoir in the injection zone and with distance from the well. The duration of the contact of LRW solutions with the reservoir sands imitated the actual conditions of the reservoir and was 50 hours (injection cycle) or a longer time (up to 3 months, imitation of repeated injection). All the sorption experiments performed in hermetic Teflon vessels emplaced in metal autoclave. Various parameters of interaction in this ternary system have been studied: dependence of sorption on $\mathrm{pH}$, on the time of contact of sand with LRW solutions, leaching of initial sand, dissolution of corrosion products, etc.

In order to reveal and analyse the main phases responsible for sorption of radionuclides the combination of Mossbauer spectroscopy, XRD, SEM-EDX, TEM, alpha-track radiography and Raman spectroscopy were involved.

\section{Results and discussion}

Modeling of radionuclide spreading in the area of underground isolation requires the determination of phases that bind individual radionuclides, as well as identifying the mechanisms of retention and mobilization of radionuclides.

The main process constraining the mobility of radionuclides in the permeable horizons of the reservoir is sorption on different surfaces of the sandy rocks minerals and precipitates of LRW. The migration behavior of radionuclides is different, with varying phases that play a dominant role in their sorption. Alpha track radiography, optical microscopy and SEMEDX analyses revealed the definite phases of preferential sorption of $\mathrm{Pu}$ and $\mathrm{Am}$ under the conditions of injection of acidic LRW into the bearing stratum. The overwhelming part of $\mathrm{Pu}$ and $\mathrm{Am}$ is retained by the $\mathrm{Fe} / \mathrm{Cr}$ oxide phases that precipitate from the waste solution at $\mathrm{pH} 3$ and $\mathrm{pH} 4$, respectively $[2,3]$. These $\mathrm{Fe} / \mathrm{Cr}$ phases have been defined as $\mathrm{Cr}$-containing goethite $(\alpha-(\mathrm{Fe}, \mathrm{Cr}) \mathrm{OOH})$ and in the case of higher Fe concentration - hematite $\left(\alpha-\mathrm{Fe}_{2} \mathrm{O}_{3}\right)$, and Fe-containing grimaldiite $(\alpha-(\mathrm{Cr}, \mathrm{Fe}) \mathrm{O}(\mathrm{OH}))[4,5]$. 
Migration behavior of U(VI) under the reservoir bed conditions is mainly controlled by sorption onto the components of surrounding rocks, clay minerals and quartz. Some part of uranium may sorbed onto aluminium hydroxides, e.g. boehmite $(\gamma-\mathrm{AlO}(\mathrm{OH}))$ and bayerite $\left(\alpha-\mathrm{Al}(\mathrm{OH})_{3}\right)$ which precipitate at $\mathrm{pH}$ 4-8 from LNW solution.

In the sorption of $U$ and $\mathrm{Np}$, the reservoir sands themselves play a significant role $[5,6]$, which forced us to make a study of both the initial sands and the secondary phases formed after interaction with acidic waste. The alteration of reservoir sands under the action of acidic wastes was shown: rapid dissolution of siderite, oxidation of $\mathrm{Fe}^{2+}$, formation and growth of aggregates of oxides and oxy-hydroxides of $\mathrm{Fe}^{3+}$ (hematite, goethite), as well as alteration in clay minerals, including slow leaching and oxidation of $\mathrm{Fe}^{2+}$.

Acid leaching and sequential leaching of actinides after their sorption on different individual and mixed phases (sands of the reservoir, $\mathrm{Fe} / \mathrm{Cr}$ and $\mathrm{Al}$ hydroxides, clay minerals and quartz) and $\mathrm{pH}$-dependence in the range $\mathrm{pH}$ values from 4.0 to 8.0 allow us to analyze the binding mechanisms of $\mathrm{U}$ and $\mathrm{Np}$ with the solid phase.

\section{Conclusion}

In this work, the phases responsible for the preferential sorption of long-lived actinides $\left({ }^{239} \mathrm{Pu},{ }^{238},{ }^{235} \mathrm{U},{ }^{241},{ }^{243} \mathrm{Am},{ }^{237} \mathrm{~Np}\right)$ were identified. While Fe/Cr oxides and oxyhydroxides play a dominant role in the retention of $\mathrm{Pu}$ and $\mathrm{Am}$, clay minerals and $\mathrm{Al}$ hydroxides are crucial for $\mathrm{U}$ and $\mathrm{Np}$ binding. The paper discusses the mechanisms of binding of actinides to the solid phase. The results of the study can be useful for the prediction of radionuclides migration behaviour at the contaminated sites in which waste of different composition can get into the environment.

This work was financially supported by the Russian Science Foundation (grant number 16-13-00049).

\section{References}

1. A.I. Rybal'chenko, M.K. Pimenov, P.P. Kostin et al., Glubinnoe zakhoronenie zhidkikh radioaktivnykh otkhodov (Deep Disposal of Liquid Radioactive Waste) (Moscow, IzdAT, 1994). In Russian

2. I.E. Vlasova, E.V. Zakharova, A.V. Volkova, A.A. Averin, S.N. Kalmykov, Radiochemistry, 56, 207-215 (2014)

3. Stepan N. Kalmykov, Irina E. Vlasova, Anna Yu. Romanchuk et al., Radiochimica Acta, 103, 175-185 (2015)

4. A.Yu. Romanchuk, I.E. Vlasova, I.V. Gusev et al., Radiochemistry, 58, 662-667 (2016)

5. Irina Vlasova, Anna Romanchuk, Anna Volkova et al., MRS Advances (2017)

6. I.V. Gusev, A.Yu. Romanchuk, I.E. Vlasova et al., Radiochemistry 60, 440-443 (2018) 